\title{
La Crítica de la razón pura: una antología hispanoamericana Luis Eduardo Hoyos y Pedro Stepanenko(eds.)
}

\author{
Juan Carlos Acosta Domínguez
}

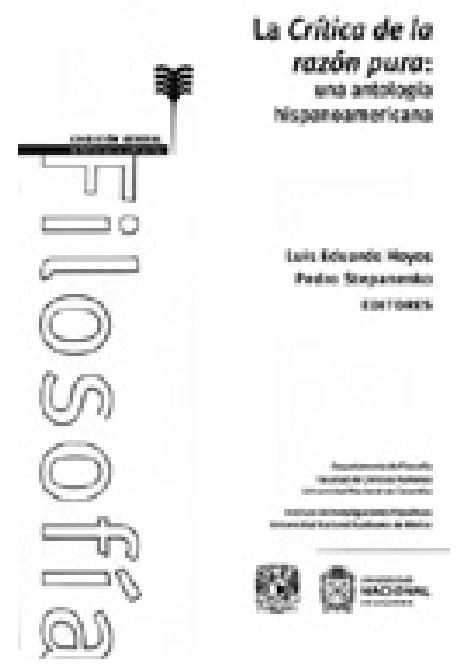

Pedro Stepanenko y Luis Eduardo Hoyos (eds). La Crítica de la razón pura: una antología hispanoamericana. Ciudad de México: Instituto de Investigaciones Filosóficas y Universidad Nacional de Colombia, 2017.
La obra de Kant — sobre todo la perteneciente al periodo crítico- constituye un punto central dentro de la historia de la filosofía. Su influencia e impacto marcaron un antes y un después en la forma misma de hacer filosofía, en cómo se estudia y concibe de manera crítica la razón, así como nuestras facultades de conocimiento. A lo largo del siglo xx el panorama de estudios y publicaciones referentes a la obra de Kant ha estado dominado por intérpretes alemanes, ingleses y norteamericanos como: N. Kemp Smith, P. Gayer, B. Stroud, P. Strawson, J. Bennett, S. Körner, E. Cassirer, J. Harnack, R. Verneaux, C. Eusebi, A. Henry, entre otros. 
Éstos han sido los referentes canónicos y obligados que todo estudiante de filosofía y especialista deben consultar para conocer a profundidad la génesis y estructuración del pensamiento sistemático kantiano y los campos de conocimiento en los cuales nuestro autor tuvo un gran impacto: epistemología, ética, moral, política, religión, estética, filosofía de la ciencia, metafísica, ontología, etcétera. Se ha consolidado la creencia de que todo lo referente a los estudios kantianos es un "producto de importación" destinado sólo a traducirse y comentarse — en un segundo momento- en las diversas partes del mundo, en especial en el continente americano donde, dicho sea de paso, el corpus kantiano siempre ha tenido una muy buena acogida en los círculos académicos.

No obstante, durante la segunda mitad del siglo xx y lo que corre del xxi el mundo hispanoparlante dedicado profesionalmente a la filosofía ha venido desarrollando y consolidando su creciente interés en la obra del filósofo de Königsberg, a través de un nutrido trabajo de artículos de primer nivel que compiten en calidad y conocimiento con los espitulados por el canon. Finalmente, éstos se han materializado en la compilación que aparece bajo el título Crítica de la razón pura: una antología hispanoamericana, realizada por Luis Eduardo Hoyos y P. Stepanenko. En ésta es posible encontrar una serie de enfoques muy actuales, que permiten al lector en lengua española tener un primer acercamiento — complejo y detallado- a las partes medulares del pensamiento filosófico de Kant.

El libro cuenta con once artículos, los cuales abordan y desarrollan nuevos enfoques sobre temas kantianos clásicos. En algunos casos, los autores muestran ciertos errores e imprecisiones en los que Kant — desafortunadamente- incurrió al momento de moldear su proyecto filosófico, como lo comprueban las aproximaciones críticas que realizan en sus trabajos.

El contenido de la presente antología inicia con "Los marcos doctrinales y la apertura fenomenológica: vías de la exploración kantiana" del filósofo venezolano Erza Heymann. Él muestra que las aproximaciones subjetivistas surgidas como herramientas interpretativas de la teoría de la experiencia en Kant son erróneas. En 
consencuencia, defiende la tesis de que el concepto de experiencia en Kant debe ser entendido como un encuentro directo con los objetos -en un sentido práctico- y no meramente desde un aspecto teórico.

En el texto "La estética trascendental” del filósofo mexicano Álvaro Peláez Cedrés se defiende el "argumento geométrico", el cual permite comprender por qué Kant pudo concebir la sensibilidad y el entendimiento como dos facultades mentales diferentes en un sentido ontológico-, que a su vez desempeñan funciones específicas por medio de las cuales el sujeto obtiene conocimiento. La geometría euclidiana permitió, como tal, que el espacio sea una intuición pura a priori, por medio de la cual la sensibilidad se convierte en un elemento con valor epistémico fuerte, con pretensiones objetivas. Aunado a ello, Peláez Cedrés trae a colación otro eje interpretativo en torno a la versión conceptualista de contenidos mentales - motivado por los trabajos de John McDowell-, donde argumenta que la mente debe entenderse como un todo unificado.

La filósofa colombiana Lucy Carrillo presenta "Idealidad y realidad del tiempo", una apuesta interpretativa donde lleva a cabo un profundo estudio del concepto de tiempo expuesto en la estética trascendental. Enfoca su atención en el tratamiento que Kant realiza sobre la exposición metafísica de dicho concepto. En un segundo momento, la autora trata de brindar una respuesta a cómo debe ser entendido el problemático concepto de "autoafección" que introdujo el filósofo alemán, aludiendo a la conexión que éste tiene con la analítica y la dialéctica trascendentales.

El especialista español en la obra kantiana J. L. Villacañas presenta "La deducción trascendental: la prehistoria del argumento", con el cual ofrece un hilo explicativo para dilucidar por qué la deducción trascendental de las categorías, en el fondo, termina siendo un pasaje oscuro de entender y no una herramienta epistémica fuerte. Villacañas se encarga de demostrar por qué Kant terminó complicando mucho las cosas, en tanto que intenta conciliar la concepción del entendimiento como facultad pasiva y la sensibilidad como facultad activa, pasando por alto algunos detalles cruciales. 
"Deducción trascendental: refutación o negociación" es el nombre del texto del filósofo colombiano Gonzalo Serrano Escallón, en el cual intenta dejar de lado la falsa creencia de que la deducción trascendental de las categorías sea vista como una especie de refutación del escepticismo de segundo grado. En su lugar, propone un acercamiento al problema como una especie de negociación entre dogmatismo y escepticismo; lo que se debería de pretender -en palabras del autor- es un reconocimiento de los elementos de naturaleza a priori, que moldean y determinan nuestro conocimiento.

El trabajo "Apercepción y objetividad en la Crítica de la razón pura" corre a cargo del filósofo mexicano Pedro Stepanenko, en él se encarga de estudiar a profundidad la "deducción larga o subjetiva" de las categorías y el nexo que tienen con el concepto de unidad sintética de la apercepción, la cual, a su vez — piensa Stepanenko-, expone la necesidad de pensar en términos objetuales. Sumado a ello, trata las dos maneras para entender -el desarrollo y las implicaciones epistémicas - del concepto de autoconsciencia en el corpus kantiano.
Mario Caimi con su texto "El esquematismo de los conceptos empíricos" aborda el complejo problema del esquematismo trascendental. El filósofo argentino —contrario a lo que ha pensado la tradición - se opone a concebir los conceptos empíricos como los elemenos que permiten al sujeto hablar de objetos particulares de manera inmediata. Caimi aventura la hipótesis de cómo estos conceptos deben ser esquematizados de manera correcta, para que sean aplicados a los objetos que refieren y así prevenir que queden reducidos a simples particularidades. Para lograrlo, Caimi considera vital la mediación de un esquema para que los conceptos empíricos, en efecto, logren referirse de manera directa y justificada a los objetos.

En "Fenómenos psico-físicos y causalidad" Claudia Jáuregui centra su atención en la necesidad de encontrar un concepto fuerte de causalidad que permita comprender y explicar la naturaleza de los fenómenos mentales y físicos que constituyen al ser humano. Jáuregui recalca que el problema surge del hecho de que Kant restringe la aplicación del concepto de causalidad a fenómenos físicos, dejando de lado 
su vida mental y llevándonos a cuestionar: ¿cómo se realiza la articulación y unificación de la realidad interna del sujeto? En consecuencia, la autora ofrece una respuesta analizando el potencial del concepto de causalidad presente en la Crítica del juicio.

Otro de los artículos más importantes y reveladores es el del filósofo mexicano J. Ornelas: "El laberinto del escepticismo en la Critica de la razón pura: la refutación del idealismo", ahí cuestiona abiertamente el que aceptemos que el idealismo trascendetal fue diseñado única y exclusivamente para refutar al escepticismo. De hacerlo advierte el autor- inevitablemente nos conduciría a lidiar con diversos problemas y obstáculos muy complejos en términos epistémicos. Para Ornelas, el primer obstáculo que sale a la luz es que el mismo Kant nunca explica de manera clara en la Crítica de la razón pura qué entendía por escepticismo, por ello, resulta muy complejo establecer si hay una corriente escéptica dominante y bien delimitada en dicha obra, la cual pueda enfrentar y refutar en su totalidad el idealismo trascendental.

Como piensa Ornelas, un primer enfoque develaría que Kant, en el fon- do, pretendió confrontar su idealismo trascendental contra el escepticismo en general. Esto conduce, de manera necesaria, a identificar y clasificar los propósitos centrales de las tres propuestas escépticas posibles, que se desprenden directamente de Descartes, Hume y Pirrón. La división del escepticismo, de acuerdo con Ornelas, debe responder a la modalidad "sustantiva" $y$ la "metodológica". La primera hace énfasis en problematizar — desde un enfoque metafísico y radical— la posibilidad de llegar al conocimiento en términos generales.

La segunda modalidad está más enfocada en dudar como tal de los elementos aportados, con los cuales se pretende justificar nuestro conocimiento en todos los niveles. El escepticismo en su faceta metodológica no desea clausurar nuestra posibildiad de conocer, todo lo contrario, su objetivo consiste en buscar un fundamento sólido a partir del cual el conocimiento - particular y científico- pueda justificarse y utilizarse en distintos niveles como lo comprueban Descartes con su "duda metódica" y Hume con su filosofía empirista. Por ello J. Ornelas llega a la conclusión de que 
en Kant sólo es posible aventurar dos interpretaciones respecto a lo que entendía por escepticismo en la Critica de la razón pura.

La primera suposición gira en torno a que Kant trató de subsumir las posturas cartesiana, humeana y pirónica en el mismo término, de ser el caso, acarrearía muchos problemas, pues cada una pretende cosas distintas epistémicamente hablando. La segunda, sostiene que el filósofo alemán nunca pudo diferenciar el escepticismo sustantivo del metodológico.

Alejandro Rosas, en "Perspectivas en conflicto: sobre la prueba indirecta a favor del idealismo trascendental", retoma el problema que aparece en la prueba indirecta. Éste — según Rosas — radica en que la razón kantiana termina postulando dos ideas contradictorias cuando se pretende organizar y dar sentido a toda la serie de elementos que van de lo condicionado a lo incondicionado, y cuando busca dar cuenta de lo sensible e inteligible. Por tal motivo, nuestro autor considera que una respuesta clara a dicha problemática podría hallarse si se analiza a detalle el contenido argumentativo en el apartado de la idealidad trascendental.
Luis Eduardo Hoyos con "Kant y el escándalo de la libertad" emprede la dura empresa de reconstruir la tercera antinomia de la razón, abarcando tanto la solución como las consecuencias que inevitablemente se desprenden de ésta. Hoyos puntualiza que el dualismo ontológico y causal defendido por Kant, por una parte, choca con la idea de que tanto determinismo como libertad puedan convergir armoniosamente. Por otro lado, termina reduciendo el asunto al hecho de que o somos libres o nos encontramos completamente determinados.

Finalmente, el filósofo Eduardo Molina presenta "El interés práctico de la razón en el canon de la razón pura”, donde detalla por qué el canon es el punto clave utilizado por Kant para darle unidad sistemática a la razón. Molina se traslada al ámbito práctico y analiza el motivo por el cual, sino existieran los tres ejes clave en los que la razón se apoya, a saber: libertad trascendental, Dios y la esperanza, en una vida futura sería imposible dar sentido y operatividad al principio de "ejecución de la moralidad".

En conclusión, todos los artículos referidos, con sus diversos matices 
interpretativos, cumplen la honorable labor de acercar, tanto al lector amateur como al mundo filosófico académico de habla hispana, los nombres y las obras de los intérpretes más importantes que existen actualmente en nuestra lengua. Nos ofrecen lecturas innovadoras respecto a los tópicos kantianos más relevantes de la tradición filosófica, los cuales, sin duda, cumplen con el máximo rigor posible. 